Announcement

\title{
The European Nutrition Leadership Programme
}

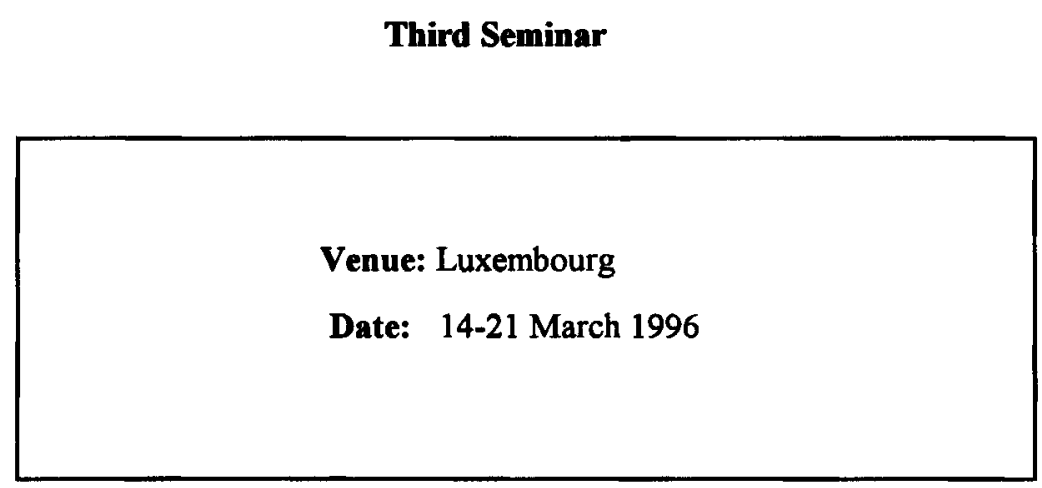

The objective of this programme is to organize advanced training seminars regularly with an emphasis on topics such as communication of nutrition science, future strategies and new frontiers in nutrition research, nutrition science and nutrition health in Europe; nutrition within European health policies.

The programme is formulated for advanced final year $\mathrm{PhD}$ students and postdoctoral fellows in human nutritional sciences in Europe. The seminar will be held on 14-21 March 1996 in Luxembourg.

For details contact: Mrs R. Hoogkamer-Weijman, VLAG Graduate School, c/o Department of Human Nutrition, Wageningen Agricultural University, PO Box 8129, 6700 EV Wageningen, The Netherlands

Telephone: +31.8370 .84214 ; Fax: +31.8370 .83342$

Application forms will be accepted until 15 November, 1995. 